\title{
El rol de la comunidad de indagación en el espacio público escolar
}

\section{Carlos Espinoza Díaz}

Estudiante de Pedagogía en Filosofía Universidad Alberto Hurtado - Chile espinozadiazcarlosantonio@gmail.com http://orcid.org/oooo-0001-6246-5354

Carolina Arredondo Ramírez

Magíster Filosofía Política

Universidad Alberto Hurtado Universidad San Sebastián - Chile caarredor@gmail.com

http://orcid.org/0000-0002-6246-7234

Artículo de reflexión

Recepción: 15 de enero de 2019 Aprobación: 06 de marzo de 2019 https://doi.org/10.19053/22160159.v10.n23.2019.9693

\section{Resumen}

Uno de los problemas de la sociedad moderna es el abandono voluntario de la comunidad y del espacio público. Las tecnologías individualizadas, el consumismo, la competitividad y las actividades privadas con fines de lucro se han apoderado del interés colectivo de la sociedad. La educación ha tomado el mismo rumbo, al adaptar prácticas del espacio público que son apropiadas a los intereses particulares de los grupos que lideran aquellos proyectos. No es de alarmarse que las relaciones comunitarias se vuelvan líquidas y sin importancia para las personas, colectividades y para el propio Estado. Sin embargo, ¿qué importancia tiene el espacio público en la escuela? ¿Cómo se expresa la comunidad de indagación en el espacio público de la niñez? Estas preguntas pretenden ser el hilo conductor de un diálogo entre comunidad de indagación, espacio público e infancia. En consecuencia, queremos situar a la comunidad de indagación como el punto de partida en la construcción de ciudadanos libres, democráticos, tolerantes, comunitarios, solidarios y conscientes del rol social político del cual son partícipes.

Palabras claves: infancia, comunidad de indagación, educación, espacio público, emancipación 


\title{
The role of inquiry community in school public space
}

\begin{abstract}
One of the problems of modern society is the intentional abandonment of the community and of the public space. Customized technologies, consumerism, competitiveness and profit-driven private activities have taken over society's shared interest. Education has set the same course, adopting public space practices which are appropriate to particular interests of those groups leading such projects. It is not concerning that community relationships become liquid and nonsensical for people, collectivities and the State itself. Nonetheless: What is the importance of public space in the school? How does inquiry community express itself in childhood's public space? These questions intend to be the unifying thread of a dialog among inquiry community, public space, and childhood. Thereupon, we want to position the inquiry community as a starting point in the building up of free, democratic, broadminded, communal, and supportive citizens who are aware of their social and political role.
\end{abstract}

Key words: childhood, inquiry community, education, public space, emancipation

\section{Le rôle de la communauté d'apprentissage dans l'espace public scolaire}

\section{Résumé}

L'un des problèmes de la société moderne est l'abandon volontaire de la communauté et de l'espace public. Les technologies individualisées, la consommation, la compétitivité, et les activités privées à but lucratif ont fait main basse sur l'intérêt collectif de la société. L'éducation a suivi la même voie en adaptant des pratiques de l'espace public propices aux intérêts particuliers des groupes dirigeant ces projets. Il n'est pas étonnant que les relations communautaires deviennent fluides et sans importance 
pour les personnes, les collectivités, et l'État lui-même. Toutefois, quelle est l'importance de l'espace public dans les écoles ? Comment la communauté d'apprentissage est-elle exprimée dans l'espace public des enfants ? Ces questions visent à être le fil conducteur d'un dialogue entre la communauté d'apprentissage, l'espace public, et l'enfance. Par conséquent, nous cherchons à prendre la communauté d'apprentissage comme le point de départ de formation de citoyens libres, démocratiques, tolérants, communautaires, solidaires, et conscients du rôle social et politique auquel ils participent.

Mots-clés : enfance, communauté d'apprentissage, éducation, espace public, émancipation

\section{O rol da comunidade de indagação no espaço público escolar}

\section{Resumo}

Um dos problemas da sociedade moderna é o abandono voluntário da comunidade e do espaço público. As tecnologias individualizadas, o consumismo, a competitividade e as atividades privadas com fins lucrativos, têm se apoderado do interesse coletivo da sociedade. A educação tem tomado o mesmo caminho, adaptando práticas do espaço público que são apropriadas aos interesses particulares dos grupos que lideram aqueles projetos. Não é de se alarmar que as relações comunitárias se tornem líquidas e sem importância para as pessoas, coletividades e para o próprio Estado. Entretanto, que importância tem o espaço público na escola? Como se expressa a comunidade de indagação no espaço público da infância? Estas questões pretendem ser o fio condutor de um diálogo entre comunidade de indagação, espaço público e infância. Em consequência, queremos situar à comunidade de indagação como ponto de partida para a construção de cidadãos livres, democráticos, tolerantes, comunitários, solidários e conscientes do rol sócio-político de que são participantes.

Palavras-chave: infância, comunidade de indagação, educação, espaço público, emancipação 


\section{Introducción}

Se asume que la definición de infancia es una tarea ya resuelta por varios autores que se han dedicado a teorizar sobre el tema y la han definido, no como un periodo de tiempo, sino como una condición social de toda persona humana. Hoy es habitual referirnos a los niños y niñas como estudiantes, porque la sociedad actual ha predispuesto que en la infancia se eduque a las personas; en contraste con épocas anteriores, en las cuales la infancia cumplía labores de mano de obra o esclavitud. Por ende, una de las tareas de la sociedad ha sido organizar la vida de los ciudadanos según los intereses que priman por sobre la comunidad.

Dependiendo de los objetivos sociales, ha variado la condición de las personas y la función que cumplen en la sociedad. La sociedad moderna ha definido que la infancia sea ocupada por el Estado para formar y educar a los niños y niñas, es decir, los infantes van perdiendo libertad y son obligados a abandonar el espacio público de sus barrios, casas y colegios, porque deben tecnificarse según la necesidad de desarrollo económico que prima en estos tiempos, lo que a la vez conlleva el comenzar a transitar en el mundo de lo privado, el cual les exige competir por ser siempre los mejores, en desmedro del juego y de la libertad que a esa edad debiesen vivir.

Asimismo, laligación delainfancia alos procesos sociohistóricos de la época son determinantes para la vida de los infantes, pues la niñez misma termina siendo utilizada por las políticas públicas de cada Estado y conducida a la prisión cultural que domina el ambiente social. En este trabajo describiremos algunas propuestas, ideas y conclusiones que emanan de la experiencia del Taller de Filosofía con Niños y Niñas [FcNN] que se realiza actualmente en el Colegio San Francisco de Asís de La Florida, Santiago de Chile, desde el segundo semestre de 2018 a la fecha. La didáctica trabajada en el taller ha permitido recoger información relevante para elaborar algunas conclusiones - somos conscientes de que podemos obtener nuevas conclusiones y de que esta experiencia es solo el comienzo de nuestras prácticas pedagógicas con los niños y niñas en nuevos talleres-. En esta ocasión la metodología utilizada se llama árbol de efectos, que busca definir los efectos más importantes del problema en cuestión, al analizar y verificar su importancia. "Se trata [...] de tener una idea del orden y gravedad de las consecuencias que tiene 
el problema que se ha detectado, lo cual hace que se amerite la búsqueda de soluciones" (Ortegón, Pacheco \& Prieto, 2005, p. 42).

La primera parte del escrito propone una breve reflexión sobre el espacio público actual en la escuela. Presenta las contradicciones entre lo que se define como público y el rol que cumple cada miembro de la comunidad, como también la normalización del ideario de la autoridad que ejerce la soberanía de dominar y controlar los acontecimientos y los tiempos en el aula.

En segundo lugar, reflexionamos sobre la normalización que ha adquirido el sistema educativo en torno al control, y cómo a la vez este mismo sistema educativo es controlado por el sistema económico dominante, que hace creer que las personas ejercen un grado de libertad, en desmedro de ceder las voluntades de elegir. Sin embargo, ya no es importante para la comunidad ni para la sociedad interrogarse si efectivamente la escuela y el aula son públicas, y si debe ser transformada realmente en un lugar democrático, inclusivo, tolerante, etc., donde el rol adultocentrista reduce el espacio para que niños y niñas accedan a la experiencia de ser protagonistas de sus propias decisiones.

Por último, proponemos la Comunidad de Indagación de niños y niñas [CiNN], como la invitación que puede abrir las puertas de la prisión escolar y volver a entregar la tutela del aprendizaje a los mismos niños y niñas, sin el miedo de que se pueda ejercer algún grado de represión. Por ende, entendemos la CiNN como un proceso colectivo de aprendizaje que transita entre la filosofía, las artes, el juego y la creatividad, y en la que todos sus miembros "trabajan para ser capaces de entender el punto de los demás y se esfuerzan solidariamente por descubrir el sentido del mundo y de la sociedad en la que viven" (Accorinti, 2014, p. 13).

\section{El espacio público en la escuela}

El cambio cultural, además de sobrellevar cambios tecnológicoseconómicos, acelera un cambio ético de la humanidad que obliga a pensar nuevamente las definiciones sobre lo público, especialmente en la escuela, ya que no basta con explicitar que existe una escuela con vocación pública, ni tampoco una escuela pública. Tal manifiesto evidencia contradicciones, puesto que, si la educación pública está 
en crisis, es porque también el espacio público de las escuelas se ha privatizado, ya sea por la orientación política partidista de los sostenedores, por el rol que cumplen los y las docentes en la escuela o por la imposición de un currículum establecido para todo el sistema educativo. Por tanto, para que una escuela se reconozca como pública requiere mucho más que depender del Estado o poseer el título de pública.

Nuestra propuesta apunta a replantear la definición de lo público en la escuela, reflexión necesaria para poder definir los objetivos educacionales y el rol que cumplirá cada agente educativo. Partimos del supuesto de escuela afirmado por Gomes (2011), quien plantea diversas reflexiones sobre el contexto escolar, no con el afán de volver a controlar todo lo ya existente, sino para buscar la mejor forma posible de participación de todos los agentes, y en especial, volver a proponer la infancia como una etapa de formación y participación en el espacio público educativo, transformando la tradición de subyugar el espacio público de la infancia a los intereses de los adultos dominantes: "Cuando hablamos de la escuela, pensamos en los sujetos y en los procesos que atraviesan su vida cotidiana, así también en las relaciones que se van tejiendo en los objetivos y en las finalidades de una educación escolar de calidad" (p. 165).

De esta manera, la infancia debe recuperar la autonomía que ha perdido y que históricamente le ha sido arrebatada por el ideario adultocentrista, el que ha utilizado tanto a la familia y a la educación como agentes dominantes, al punto de construir en los hogares y luego en las escuelas, las primeras cárceles por las que empezarán a transitar los niños y niñas.

¿Qué sentido tiene hoy reclamar el espacio público de la infancia, en una cultura que ha desechado este espacio como lugar de encuentro social y democrático? ¿Es posible asumir que los adultos están preparados para abrir las puertas de la cárcel donde están encerrados el poder y dominio, y así perder el control sobre la infancia? ¿Es la escuela realmente un lugar democrático y participativo? Pareciera que soplan vientos de cambios culturales más drásticos que antes, sin embargo, a pesar de haber pasado por radicales vicisitudes, el ser humano ha dejado en el olvido el sentido de la comunidad. No obstante, las preguntas planteadas anteriormente no han sido tratadas en el ámbito escolar, al contrario, 
la escuela chilena también se entregó al hedonismo dominante en sintonía con la cultura, dejando de lado el cumplimiento del rol público.

Moulian (1998) describe cómo funciona el espacio público de un mall. Ciertamente, si reemplazamos la palabra mall por escuela, la idea que expone el autor también serviría para poder definir el aparente engaño en definir a la escuela pública como un espacio comunitario de aprendizaje, considerando las actuales formas de gestión educativa.

El mall -fijémonos en cómo esta definición funciona también para escuela - es un espacio privado con aspecto de espacio público, con acceso en apariencia libre, pero sometido a discreto control, con sus entradas, salidas y circulación vigiladas por cámaras invisibles. "Pero esos guardias silenciosos parecen estar allí para otorgarnos protección, en ningún caso para proteger las instalaciones. Sin embargo, ningún movimiento escapa a su mirada" (Moulian, 1998, p. 55).

Lo anterior define y ejemplifica a la perfección a la escuela chilena, aquella que pregona una vocación de servicio público controlando todos los espacios, puertas y rincones. No basta con educar en un ambiente cerrado con un guardia llamado profesor, que junto con la tarea de vigilar y castigar ${ }^{1}$, debe enseñar, convirtiendo el espacio escolar en una guardería correccional que tiene como misión modelar y normalizar la infancia de acuerdo a los intereses políticos-económicos dominantes.

Lo que el sistema dominante ofrece y promete actualmente es un futuro inmejorable para la vida de aquellos que pasen por esas aulas, partiendo por conocimientos humanos, técnicos, sociales, comunitarios, etc., a lo cual, los padres de familia se acercan voluntariamente anonadados por la finalidad de proyectar en sus hijos sólidos conocimientos sobre el mundo y la técnica. Pero la realidad dista mucho de estas promesas. La Unesco emitió un informe sobre la enseñanza y el aprendizaje de las escuelas, en el cual formula un lapidario comentario, que en muchas ocasiones ha sido dejado de lado, porque al parecer, son realidades aisladas:

$1 \quad$ En referencia al ideario que plantea Foucault en Vigilar y castigar (2018), donde la tarea del sistema escolar se asemeja al ser custodios en el espacio público de la escuela, que debe castigar cualquier acto que rompa la normalidad de la vida escolar, de manera de resguardar las tradiciones. 
En el mundo entero, 250 millones de niños - muchos de ellos, de medios desfavorecidos- no adquieren ni siquiera las nociones básicas de lectura, escritura y aritmética, por no hablar ya de otras competencias que necesitan para conseguir un trabajo digno y llevar una vida que les haga sentirse realizados. (Unesco, 2014, p. 22)

Si los y las estudiantes infantes no aprenden los conocimientos necesarios para enfrentar la vida, ¿a qué van a la escuela? La respuesta la podemos encontrar en algunos esbozos que ya hemos mencionado. Los infantes van a la escuela para ser sometidos e instrumentalizados por el sistema, mediante el adoctrinamiento carcelario al que se somete toda la sociedad, es decir, en la infancia parte aquella manipulación social que hace a los infantes absolutamente dependiente de los padres, tutores, profesores, etc. El infante carece de autonomía. El imaginario adultocentrista controla como un titiritero la vida de los niños y niñas, imputando poder mediante la autoridad que le ha conferido la facultad de solo ser adulto.

Los niños y niñas son dirigidos como marionetas sin libertad ${ }^{2}$, a merced de lo que otros hagan por ellos. Se les impide tomar sus propias decisiones. Son conducidos al lugar de aprendizaje que los guiará a conveniencia: la escuela, la prisión.

\section{En la prisión desde la infancia}

La evolución cultural ha llevado a la sociedad a redefinir evolutivamente los derechos humanos. Desde la Revolución francesa se marca un punto de partida de la justicia social de la humanidad, al proponer la importancia de los derechos humanos como centro de la vida de la sociedad, con la ayuda de las convenciones internacionales sobre derechos humanos e infancia y la importancia de la educación hasta la formación de asociaciones feministas y de colectivos de diversidad sexual. En ese contexto, nos encontramos en el punto de partida de nuestra reflexión crítica: la prisión.

2 Concepto utilizado en el libro El alma de las marionetas de Gray (2015). En este trabajo se asocia a las marionetas con los y las estudiantes, que son utilizados por el sistema educativos como unos simple cuerpos sin vida, que deben ser movidos según el ideario del sistema. 
Esta fortaleza transversal ha sido diseñada y adaptada para que toda la sociedad que vive en ella sienta libertad y autonomía. El cautiverio es nuestro reflejo feliz del Edén. Si bien, se han manifestado en gran parte de nuestra historia procesos sociales de igualdad o equidad, en la mayoría de los casos no han tenido la trascendencia que buscaban. Desde la Revolución francesa, los grandes principios humanos han ido declinando al punto de ser remplazados por el hedonismo cultural del capitalismo. El cambio radical que vive la cultura no parte de los derechos humanos, sino de la propaganda económica que impulsa el seguimiento de estereotipos, roles, pérdida de libertad, desinterés colectivo y el abandono del espacio público como lugar de encuentro, lo cual, desgraciadamente, la humanidad sigue con un afán escandaloso. Pareciera que el niño o niña, después de pasar por el primer ciclo de educación escolar, es condenado socialmente a habitar la prisión y adaptarla como su zona de confort.

El modelo económico capitalista ha impuesto como lugar de encuentro la prisión, que es el lugar donde

el gobierno puede disponer de la libertad de la persona y del tiempo del detenido; entonces se concibe el poder de la educación que, no solo en un día, sino en la sucesión de los días y hasta de los años, puede regular para el hombre el tiempo de vigilia y de sueño, de actividad y de reposo, la cantidad y la duración de comidas, la calidad y ración de los alimentos, la índole y el producto del trabajo, el tiempo de oración, el uso de la palabra, y por así decirlo, hasta el del pensamiento, esa educación que, en los simples y breves trayectos del refectorio al taller, del taller a la celda regula los movimientos del cuerpo e incluso, en los momentos de reposo, determina el empleo del tiempo, esa educación en una palabra, que entra en posesión del hombre entero, de todas las facultades físicas y morales que hay en él y del tiempo en el que él mismo está inserto. (Unesco, 2015, p. 272)

Desde el ideario adultocentrista, la prisión ejerce control sobre la vida de los que ahí se encuentran, en la escuela sobre los estudiantes, en la casa sobre los hijos, en las relaciones de pareja con el más débil, etc. La libertad y la educación para la vida se plantean o discuten en un lugar que es tierra de nadie, y que a la vez, obedece a un ideario político que ha devenido en una promesa de libertad, que al menos lleva doscientos años - desde la Revolución francesaesperando poder asumir el liderazgo que merece en la humanidad. 
Pareciera que el sentido común debe poner en práctica los ideales de justicia que reclaman innumerables seres humanos que han sido violentados por las prácticas culturales que terminan por subyugar la libertad individual (Arendt, 2015) de emancipación en la escuela, para transformarla en una libertad hedonista del consumo. Por eso resulta imperativo replantearnos el problema filosófico del para qué educar.

Nuestras costumbres siguen siendo sometidas por las culturas dominantes de los reyes de antaño. Hemos pasado al dominio del capital, en el cual la educación se entiende como la garante del buen comportamiento de la sociedad y, evidentemente, del comportamiento de los ciudadanos. Las instituciones escolares se transforman en una máquina de producir ciudadanos prototípicos, que no cuestionan su aporte a la humanidad, sino la calidad de la mano de obra de los estudiantes al salir de los distintos niveles educativos, en desmedro de los valores y propósitos humanos de la educación, tal como sostiene McLaren:

En general los teóricos críticos de la educación afirman que las políticas culturales de las escuelas inculcan histórica y actualmente una ideología profesional meritocrática, racionalizando la industria del conocimiento por niveles de clase social; reproducen la desigualdad, el racismo y el sexismo; y fragmentan las relaciones sociales democráticas mediante la enfatización de la competitividad, el androcentrismo, el logocentrismo y el etnocentrismo cultural. (1994, p. 48)

Por el tipo de educación que se enseña en la escuela, a partir de la primera infancia, la sociedad se encuentra sometida a la prisión y al abandono del espacio público. Este espacio ha sido reducido a una normalización continua de la vida de las personas en el espacio privado, que potencia, al mismo tiempo, el abandono del espacio privado mediante mecanismos de represión, como son en algunos casos los diagnósticos clínicos. Cualquier conducta que vaya en contra de las normas se considera como una anormalidad que rompe con el orden. Por consiguiente, el niño o niña que reacciona contracorriente es considerado como un anormal por las autoridades civiles de la escuela.

En consecuencia, el ideal colectivo de libertad o emancipación que se debe vivir en el espacio público de la escuela ha sido absorbido mercantilmente, reduciendo la libertad al espacio de la 
prisión escolar, la cual opera como una prisión normativa donde hoy se imparte la educación y que no tiene interés en cambiar el modelo y las formas de enseñar, porque sencillamente no han cambiado los objetivos o a causa de la crisis que vive el quehacer docente. Replantearnos los objetivos es de tal impacto que no solo requiere un esfuerzo por hacer notar la necesidad de una nueva educación, sino que tenemos que comenzar a visualizar desde una postura reflexiva la forma de educar, desde el cómo, para qué y con quién; y al tiempo, invitar a re-mirar de manera crítica los actuales planteamientos que dominan el escenario educativo. El desafío, por lo tanto, no es menor. La invitación es a vislumbrar la educación como un proyecto transformador desde un colectivo subversivo que trate de romper las puertas de la prisión y salir de ella, pero no solo para sentirse libre, sino para asumir la libertad como una experiencia de vida, aun cuando este ideal de emancipación sea un problema en sí mismo, porque no preexiste claridad de los objetivos o del fin de la educación pública, la cual, junto al espacio público, forma parte del sistema económico dominante, que al mismo tiempo produce y reproduce mano de obra para encajar exitosamente las piezas del sistema.

El espacio privado juega a ofrecer más comodidad a la sociedad y propone alternativas educativas que la gran mayoría no puede alcanzar. La escuela pública excluye y discrimina al no entregar una educación que sea transformadoramente humana a la infancia, lo que provoca que la misma sociedad considere lo público de mala calidad, en vez de asumir que deben recuperar este espacio y potenciarlo mediante acuerdos colectivos y participativos en la comunidad. Frente a esta propuesta colectiva, los intereses privados constantemente bloquean la participación ciudadana. La trampa está en evitar que surjan respuestas sociales a los problemas educativos. La misma sociedad está constantemente en tensión en este punto y no logra ofrecer alternativas de cambios, lo que impide que emanen acuerdos transformadores al primar los intereses privados en desmedro de los colectivos. Es así como la falta de acuerdos colectivos hace fracasar cualquier propuesta social de transformación:

Tanto si decimos que su esfera específica de competencia es la pluralidad de los hombres, o que lo es el rasgo común del mundo humano, el sentido común opera, como es obvio, en el espacio público de la política y de la moral, y es este espacio el que 
necesariamente se resiente cuando el sentido común y sus juicios comúnmente aceptados ya no se sostienen, ya no tienen sentido. (Arendt, 2015, p. 78)

La educación necesita con urgencia replantearse el objetivo que persigue al educar, al menos la educación pública. Más que fomentar el perfeccionamiento de la técnica debe proponer la educación como una comunidad que tenga como meta indagar. La falta del sentido común que propone Arendt no se puede buscar en otro lugar que no sea la prisión escolar, la cual ha sido instaurada para perder libertad y dejar de lado el sentido de liberación que debiese vivir la infancia en el espacio público. Ahora bien, no solamente la libertad se pierde, sino que también la escuela le agrega un rol competidor al niño o niña, con el fin de compararlos como si fuesen una simple mercancía por tranzar. La escuela cruelmente castiga en sus prácticas educativas a los estudiantes, mediante las malas calificaciones para los niños y niñas que no logran los objetivos. Es evidente que el objetivo de la escuela pública en Chile está en constante tensión con la educación, al menos con la educación que la Unesco (2015) propone:

La visión se inspira en una concepción humanista de la educación y del desarrollo basada en los derechos humanos y la dignidad, la justicia social, la inclusión, la protección, la diversidad cultural, lingüística y étnica, y la responsabilidad y la rendición de cuentas compartidas. Reafirmamos que la educación es un bien público, un derecho humano fundamental y la base para garantizar la realización de otros derechos. (p. 7)

$\mathrm{Al}$ esconder su principal ideal que es actuar como una fábrica moderna de mano de obra y explicitar un discurso de escuela pública al servicio de la comunidad, ¿̇es culpable un ignorante de su ignorancia? Sócrates diría que no, debido a que ignora que es ignorante. Ahora bien, ¿es culpable la educación de reprimir a sus estudiantes mediante una educación que segrega, discrimina, genera odio e injusticia social? Es una pregunta que para ser respondida requiere no solo una interpretación filosófica, sino que también una comprensión histórico-cultural. No basta con decir que la educación tiene que cambiar o mejorar, también debemos cambiar los agentes educativos, el foco de la educación, los métodos y modelos educativos, la didáctica, los métodos, las estrategias, los edificios, etc. 
Como vemos, se requiere cambiar el contexto cultural en que se educa, que hasta el día de hoy se entiende como un proceso dependiente de la industria y la economía. Por más que los colectivos sociales reclamen y promuevan un cambio de mentalidad y acción, al promover la educación como un proyecto colectivo transformador, el problema es que seguimos estando prisioneros en el espacio privado que niega la salida a los ciudadanos, los cuales siguen siendo abusados a diario por los carceleros. La ley de la prisión escolar fomenta que los actos de control y calificación sigan siendo una herramienta de control escolar.

Continuando con la idea de la prisión escolar, encontramos que el ejercicio de la autoridad y de la instrucción está viciado. La enseñanza que se espera que suceda en la escuela se transforma en un discurso sin sentido, que incrementa el nivel de indiferencia de los y las estudiantes, los cuales sufren no solo la pérdida de la libertad, sino el fin de lo colectivo. Lo único colectivo que queda es que todos estamos cautivos. "La prisión es el castigo igualitario" (Foucault, 2009, p. 266). A merced del gran inquisidor que es el capitalismo, cada ser humano negocia un espacio en la prisión según su posibilidad, esperando que sus cadenas se puedan prolongar. De esta manera, el inquisidor astuto ofrece aquello que en un principio satisface rápida y fácilmente al ser humano, una educación de calidad a bajo costo, pero con el pasar del tiempo, el inquisidor va pasando la cuenta y la deuda del estudiante es más grande que sus aspiraciones humanas, quedando a merced y voluntad del astuto inquisidor.

\section{El rol de la CiNN en el espacio público de la infancia}

El rol que ha planteado la propuesta de CiNN liderada por Matthew Lipman, Anna Sharp, Walter Kohan, entre otros, propone una alternativa de educación a lo ya expuesto anteriormente, en la cual la apertura de la cárcel, por más difícil que parezca se debe realizar desde la misma aula, claro que no desde la represión a la que están acostumbrados los estudiantes, la cual provoca irremediablemente que la infancia y la adolescencia - de la que saldrán en algún momento y que mayoritariamente transitaron en sus escuelasestén colmadas de malos augurios, mala educación, una débil 
formación ciudadana, más bien discriminadora, violenta, poco tolerante, con falta de empatía y espacios solidarios (Onfray, 2002).

Es así como el objetivo de instaurar la CiNN como fundamento del espacio público escolar es de vital importancia, ya que cambia el foco educativo, además de la comprensión y la forma de entenderse con los y las estudiantes: "promoviendo en los niños y niñas un pensamiento crítico se reconoce como una actitud, que se constituye en la posibilidad de oponerse a estructuras dadas a modo de ciertas o verdaderas" (Suárez, González \& Lara, 2017, p. 233). Además, lleva a re-pensar y transformar la práctica pedagógica, en la cual el profesor y la profesora son el primer eslabón en la cadena de cambios radicales que requiere alentar la $\mathrm{CiNN}$ :

Si queremos convertir el aula en una comunidad de investigación preocupada por buscar el sentido de la propia existencia y del mundo que nos rodea, preocupada por la búsqueda de la verdad, el bien y la belleza, también pretendemos que las profesoras y profesores que se embarquen en este proyecto lleguen a pensar por sí mismos y a convertirse en una comunidad de investigación que se preocupe seriamente por su propia práctica educativa y por el papel que desde ella se pueda desempeñar en la transformación de nuestras sociedades. (Lipman, 1998, p. 15)

Reafirmamos que el foco de la CiNN no está centrado solamente en los estudiantes como agentes epistémicos, sino que también en los profesores y las profesoras como agentes facilitadores del conocimiento, cambio radical que a algunos les resulta peligroso, porque tendrán que ceder el poder a los y las estudiantes y dejar de ser proveedores de conocimientos sin sentido, que no significan nada para la vida de los estudiantes, al cambiar el paradigma epistemológico cultural imperante de formar brillantes discípulos a incisivos investigadores y librepensadores: "es transgresión de lo establecido [...] es un constante cuestionamiento acerca de las causas de todo lo concebible; pero también, y sobre todo, es la promesa siempre renovada de un nuevo sentido, arduamente buscada" (Ivulich, 2017, p.12), convirtiéndose la CiNN en una herramienta que permite la excarcelación de las libertades y por fin una educación que sea capaz de crear caminos a la emancipación de la infancia, porque como dice Lipman (1998), "sería poco realista esperar que se comporte justamente un chico que ha crecido entre instituciones injustas. Los que abusan de los derechos de los demás suelen ser personas que han sido ellas mismas maltratadas" (p. 38). 
El declive de la educación y toda la crisis social que ha generado una formación deficiente en la infancia y adolescencia ha provocado volver las miradas sobre las humanidades y la utilidad que tienen en el mundo hoy. Al pensar el mundo como algo realvirtual, que requiere una mayor capacidad de presencia de las humanidades que antes, "las humanidades tienen que abandonar su sujeto antropocentrado y adoptar la agenda post humana de los estudios críticos de género, de raza, de la ciencia, de los medios de comunicación, de la cultura, de los estudios animales" (Chamorro, 2017, p. 251). Mediante un trabajo comunitario indagatorio se puede realizar esto. Hay que partir del diálogo constructivo y crítico de las cosas y generar espacios de confianza entre sus miembros, así como planificar en conjunto la ruta a seguir, que contenga responsabilidades compartidas y la autorregulación.

Otro beneficio que puede entregar la CiNN es rescatar del abandono y del menosprecio al espacio público - el cual, como ya hemos mencionado anteriormente, ha perdido terreno en la educación tradicional- y volver a posicionarlo como un lugar de encuentro democrático, reflexivo y tolerante. Este espacio en común nos abre el camino para una "educación no autoritaria y antiadoctrinadora. Respeta el valor de la indagación y el razonamiento, estimula el desarrollo de modos alternativos de pensamiento e imaginación y sugiere que los niños son capaces de aprender unos de otros" (Lipman, 1998, p. 127).

La CiNN busca que los miembros actúen con autonomía, mediante una didáctica pedagógica orientada a la indagación y, por supuesto, mediante la práctica de la libertad en la escuela. La CiNN promueve un real espacio público y provoca que las prácticas anteriormente generadas en los ámbitos de prisión se puedan superar en un ambiente libre, sin la tutela de un líder o guía (Cerletti, 2003) que esté controlando y certificando el conocimiento que ha generado a lo largo del tiempo, al forjar seres humanos vacíos de principios y conocimientos, que no saben cómo hacer frente al sistema dominante y menos revelarse frente a los abusos. "El sujeto de la ética no está dotado necesariamente de un Yo estructurado, preciso, lúcido y saludable. Con frecuencia la identidad carece mucho de ello [...] cuando no de la mayor parte" (Onfray, 2013, p. 108). Es la CiNN una herramienta que también puede ser utilizada para transformar a los abusadores y carceleros, 
con la finalidad de que estas personas puedan ser conscientes del daño que provocan al utilizar la educación con fines económicos más que con fines emancipadores. Sócrates sostiene que la única forma de salir del error es saber que lo que se hace está mal o es éticamente reprochable: "Pues es evidente que, si aprendo, cesaré de hacer lo que hago involuntariamente" (Platón, 2018, p. 64).

Al mismo tiempo, la discusión sobre los fines de la educación - provocada por la CiNN- plantea interrogantes necesarias que deben abordarse en sentido de la práctica filosófica en el aula. Cuando se habla de calidad de educación en una escuela pública, es importante proponer preguntas como las que plantea Schmelkes (1995): “¿Cómo está el sistema educativo contribuyendo al logro de este conjunto de objetivos?” (p. 21). Esta misma pregunta se puede aplicar a la CiNN y a la relación con la vida ordinaria del mundo y de las personas. Resulta necesario entonces responder: ¿cómo la comunidad de indagación filosófica contribuye al constante cambio científico y tecnológico que vive la humanidad? ¿Es la CiNN una herramienta práctica para fomentar la democracia, el respeto, la libertad en el espacio público? Si la educación deja pasar este tipo de preguntas y omite el diálogo al respecto, se pierde la posibilidad de ser un actor importante en la sociedad y sencillamente la CiNN se vuelve útil a la prisión. Las preguntas éticas que cuestionan el comportamiento de las personas deben estar presentes, así como las que cuestionan constantemente al sistema capitalistamercantilista, mientras le exigen que retribuya a la sociedad parte del beneficio que ha obtenido.

La práctica filosófica es esencial para la vida de los y las estudiantes, para su presente y futuro, por lo que necesitamos que la CiNN contribuya con la mayor cantidad de herramientas posibles, y que estas sean puestas a libre disposición, con la finalidad de que sirvan para que los infantes puedan elegir qué camino trazar con sus vidas y cómo quieren abordar conscientemente la realidad social-existencial que se vive hoy en día. Hay que asumir que ellos tienen ideas propias que se pueden y se deben potenciar mediante un desarrollo de la práctica filosófica.

Lipman, Sharp y Oscanyan (1992) en referencia al objetivo de la educación, citan a Dewey para argumentar que la educación tiene que ser redefinida como el fomento de la capacidad de pensar y no cumplir la función de mero trasmisor de conocimiento. 
Por eso, la idea de estar alerta, lo que significa estar presentes epistemológicamente en el mundo, haciéndose cargo de sí mismo, se torna una necesidad imperiosa para las personas. Es deber de los y las docentes hacer que la clase de filosofía no se transforme en una bodega de almacenaje de conocimiento, sino que sea un laboratorio de creación de nuevas propuestas y que tenga como creadores a los y las estudiantes del curso. Los docentes debemos estar enfocados en estimular la investigación o indagación, en lugar de repetir (Rancière, 2007) información, que en algunos casos llega a ser desechada inmediatamente. Solo dejando de repetir potenciamos el pensamiento crítico reflexivo, autónomo, responsable y emancipador.

La propuesta rancieriana de enseñanza universal se fundamenta principalmente en la relación que el docente establece entre su saber y el alumno. En términos prácticos Rancière propone un desplazamiento del docente del rol tradicionalmente asignado para dar lugar a la emancipación del educando. (Macías, 2015, p. 77)

La función crítica parte en gran medida del haber aprendido a filosofar en la escuela. Todo aprender a filosofar produce y crea sentido entre la realidad y la conciencia de ser una persona activa en la sociedad. La conciencia de libertad de la persona también se ve potenciada mediante la construcción de herramientas lógicas, críticas, hermenéuticas, retóricas, epistemológicas, científicas, etc., que a la vez se potencian con el aprendizaje de las otras disciplinas. La CiNN busca relacionar la filosofía con las otras asignaturas que componen el currículum, tal como lo sugiere Gaete (2015), en el libro Experiencias didácticas para la enseñanza de la filosofía, donde señala que

el sentido de la filosofía en la escuela no se relaciona con aprender los contenidos disciplinares, sino con interpretar el mundo en que vivimos, en tanto son los sujetos en su devenir histórico y social los que otorgan sentido a las disciplinas desde la experiencia. (p. 33)

Es importante que la educación de la práctica filosófica sea un proceso de aprendizaje. Para que ese aprendizaje sea significativo, la CiNN debe crear los mecanismos necesarios para que las actividades que en ella se realicen, no se transformen en una mera clase de acumulación de conceptos que terminen calificando a los y las estudiantes en el ámbito de la capacidad de memoria o en 
calificaciones estándar y repetitivas. El profesor Quiroz (1992) critica la tendencia a la intranscendencia del conocimiento y a la inutilidad de enseñar materias que solo sean para acumular conocimientos:

Una tendencia de las prácticas de enseñanza es el énfasis en la memorización de datos formalistas y enciclopédicos, en detrimento de la apropiación de conocimientos y habilidades pertinentes y significativos [...] Su resultado es una simulación de apropiación del conocimiento que se plasma frecuentemente como un éxito en los exámenes y en la acreditación, pero que poco significa en cuanto a apropiación duradera de saber. (p. 215)

La CiNN ayuda a que la filosofía promueva una educación pública inmiscuida en la vida cotidiana de las personas, que tenga trascendencia en el tiempo y sea significativa para los y las estudiantes. Por el contrario, los profesores repetidores se plantean desafíos inútiles y poco didácticos y ponen mucho énfasis en las calificaciones en desmedro de la comunidad. Se enfocan en medir el contenido y no promueven ni ayudan el aprender a filosofar, ya que seguramente no entienden que la CiNN es en sí misma un proyecto filosófico.

La filosofía es por sí misma un propósito colectivo, que debe hacer reflexionar a toda la comunidad escolar. Abrir las puertas del aula para que el conocimiento que ahí se está produciendo pueda salir y ser compartido con más personas es una tarea que se ha olvidado por distintos motivos. Uno de ellos puede ser porque se ha dejado de hacer un trabajo de indagación en el aula y se ha asumido el proyecto intrascendente propuesto por el currículum, que entrega conocimientos que, en muchos casos, quedan obsoletos con respecto a la realidad que viven los y las estudiantes. Se convierten en una mera estadística archivada en el libro de clases, obtenida de un control o una prueba estandarizada.

La adaptación de contenidos pedagógicos es propia de la comunidad. Ya no es necesario tener un cronograma establecido con anterioridad para ser canon. Con esto no queremos descartar ninguna propuesta curricular, al contrario, la CiNN debe considerar esa propuesta y adaptarla a la realidad, aspiraciones y necesidades de la propia comunidad.

La finalidad de este proyecto es pensar la CiNN como un proyecto filosófico que haga frente a la educación de mercado, que ha privatizado, no solo el ámbito económico, sino que también el 
intelectual, al imponer un "esquema de dominación y discriminación, autoritario, machista y paternalista” (Alzate, 2002, p. 146). Así mismo Saavedra (2012) afirma que

la discusión filosófica se convierte para la enseñanza de la filosofía en un mecanismo que incide en la manera como los estudiantes pueden pensar sobre su propio pensamiento. Las destrezas y habilidades de pensamiento y razonamiento son solo posibles de adquirir y fortalecer por medio de la discusión y la deliberación con otros. (p. 190)

Por tanto, mediante la CiNN buscamos salir de la prisión impuesta desde la niñez, dar espacio a la infancia como agentes epistémicos válidos y construir un espacio público donde cada persona pueda emanciparse sin miedo a ser castigado o calificado por los agentes opresores.

\section{Referencias}

Accorinti, A. (2014). Filosofía para Niños. Buenos Aires: Manantial.

Alzate, M. (2002). La infancia: concepciones y perspectivas. Pereira: Editorial Papiro.

Arendt, H. (2015). La promesa de la política. Buenos Aires: Paidós.

Cerletti, A. (2003). La política del maestro ignorante: la lección de Rancière. Educação \& Sociedade, 24(82), 299-308. https://dx.doi. org/10.1590/So101-73302003000100021

Chamorro, E. (2017). Michel Foucault y los sistemas de pensamiento. Viña del Mar: Cenaltes Ediciones.

Foucault, M. (2009). Vigilar y castigar. Ciudad de México: Siglo XXI.

Gaete, M. (2015). Experiencias didácticas para la enseñanza de la filosofía. Santiago: Editorial Universitaria.

Gomes, V. (2011). Filosofía con niños ¿Camino para un pensar transformador en la escuela? Revista de Artes y Humanidades UNICA, 12(2), 160-189.

Gray, J. (2015). El alma de las marionetas. Ciudad de México: Editorial Sexto piso.

Ivulich, S. (2017). Filosofar con niños: reflexión en torno a la práctica. Río Cuarto: UniRío Editora.

Lipman, M. (1998). Filosofía en el aula. Madrid: Ediciones de la Torre. 
Lipman, M., Sharp, A., \& Oscanyan, F. (1992). La filosofía en el aula. Madrid, España: Proyecto didáctico Quirón.

Macías, J. (2015). Educación y política en filosofía con niños y niñas. Reflexiones a partir de El maestro ignorante de Rancière. Análisis. Revista Colombiana de Humanidades, 47 (86), 69-84.

McLaren, P. (1994). Pedagogía crítica y cultura depredadora. Barcelona: Paidós.

Moulian, T. (1998). El consumo me consume. Santiago: LOM.

Onfray, M. (2002). Cinismo retrato de los filósofos. Buenos Aires: Paidós.

Onfray, M. (2013). La fuerza de existir. Barcelona: Anagrama.

Ortegón, E., Pacheco, J., \& Prieto, A. (2005). Metodología del marco lógico para la planificación, el seguimiento y la evaluación de proyectos $y$ programas. Santiago de Chile: ONU.

Platón. (2018). Apología de Sócrates. Madrid: Gredos.

Quiroz, R. (1992). La gestión pedagógica de la escuela. En Ezpeleta, J., Furlán, A. (comps). La gestión pedagógica del currículum formal en las escuelas secundarias (pp. 213-224). Santiago: Unesco.

Rancière, J. (2007). El Maestro Ignorante. Buenos Aires: Zorzal.

Saavedra, M. (2012). Del aula de clase tradicional a la comunidad de investigación. Praxis \& Saber, 2(4), 179-200. https://doi. org/10.19053/22160159.1121.

Schmelkes, S. (1995). Hacia una mejor calidad de nuestras escuelas. Ciudad de México. Editor OEA.

Suárez, M., González, B., \& Lara, P. (2017). Apropiaciones y experiencias pedagógicas defilosofía e infancia en Colombia. Praxis \&Saber, 8(16), 225-247. https://doi.org/10.19053/22160159.v8.n16.2017.6184

UNESCO. (2014). Informe de seguimiento de la EPT en el mundo. Enseñanza y aprendizaje, lograr la calidad para todos. París: Unesco.

UNESCO. (2015). Educación 2030. Declaración de Incheon, y marco de acción para la realización de Desarrollo sostenible 4. París: Unesco. 